\title{
Prevalensi dan Faktor Risiko Tuli Akibat Bising pada Operator Mesin Kapal Feri
}

\section{Prevalence and Risk Factors Noise Induced Hearing Loss on the Ferry Machine Operator}

\author{
Jumali, Sumadi, Sylvia Andriani, Misbahul Subhi, Damianus Suprijanto, Wuri Diah Handayani, Abdul Chodir, \\ Fadilatus Sukma Ika Noviarmi, Leli Indahwati
}

Departemen Kesehatan Lingkungan Fakultas Kesehatan Masyarakat Universitas Airlangga

\begin{abstract}
Abstrak
Kebisingan ruang mesin dapat menyebabkan gangguan pendengaran. Tujuan penelitian ini adalah menganalisis prevalensi tuli akibat bising Noise Induced Hearing Loss (NIHL) dan faktor yang memengaruhi pada operator mesin kapal feri penyeberangan Ketapang-Gilimanuk. Penelitian observasional dengan pendekatan cross sectional ini menggunakan metode pengumpulan data dengan wawancara, pengukuran intensitas kebisingan ruang mesin dan pemeriksaan audiometri terhadap operator. Besar sampel adalah 66 operator dari 36 kapal feri yang memenuhi kriteria inklusi dipilih secara acak. Hasil studi menunjukkan 36\% kapal memiliki intensitas kebisingan $\leq 85 \mathrm{dBA}$ dan $64 \%>85 \mathrm{dBA}$. Pemeriksaan audiometri dengan nada murni pada 66 operator didapatkan $34,85 \%$ responden mengalami $\mathrm{NIHL}$. Hasil analisis regresi logistik menunjukkan faktor dominan yang memengaruhi NIHL adalah usia dan lama paparan $(p<0,05)$. Hasil uji kai kuadrat didapatkan intensitas kebisingan berpengaruh signifikan terhadap $\mathrm{NIHL}$ setelah dikoreksi dengan umur dan lama paparan $(p<0,05)$. Disarankan untuk mengurangi waktu paparan terhadap operator yang terpajan kebisingan tinggi dan menjaga jarak antara operator dengan sumber kebisingan untuk meminimalkan pajanan bising.

Kata kunci: Audiometri, tuli akibat bising, tuli sensorineural
\end{abstract}

\begin{abstract}
Engine room noise can cause hearing loss. The objective of this research was to analyze the prevalence of Noise Induced Hearing Loss (NIHL) and its affecting factors on machinery ferry operators at Ketapang-Gilimanuk. This was an observational with cross sectional design, the techniques for collecting data were interviews, noise intensity measurements and audiometric examination. The sample was 66 operators who were selected randomly after inclusion. The study results showed that $36 \%$ of ferry have noise intensity $\leq 85 \mathrm{dBA}$ and $64 \%$ have $>85 \mathrm{dBA}$. The audiometric examination with pure tone result of the 66 operators showed that $34.85 \%$ of respondent had NIHL. The age and length of exposure affected NIHL incidence $(p<$
\end{abstract}

0.05). While the noise intensity affected the incidence of NIHL $(p>0.05)$ together with age and lenght of exposure. It is important to reduce exposure time of noisy operations on workers, automation of activities and increase the distance between workers and noisy equipment to minimise the noise exposure.

Keywords: Audiometry, noise induced hearing loss, sensorineural hearing loss

\section{Pendahuluan}

Kebisingan adalah bunyi yang tidak dikehendaki yang dapat menimbulkan gangguan kesehatan dan kenyamanan lingkungan pada tingkat dan waktu tertentu. ${ }^{1}$ Kebisingan merupakan salah satu faktor risiko tuli yang sering terjadi di lingkungan kerja. Kemajuan teknologi industri dan transportasi telah memicu pemakaian mesin produksi dan penggerak yang menyebabkan suara bising di lingkungan kerja. Menurut perkiraan World Health Organization (WHO), secara global, pada tahun 2000, penderita gangguan pendengaran berjumlah sekitar 250 juta $(4,2 \%)$ penduduk dunia, sekitar 75 sampai 140 juta bermukim di Asia tenggara termasuk Indonesia. ${ }^{2}$

Pada manusia, kebisingan menyebabkan gangguan yang bersifat nonpendengaran (nonauditory) dan pendengaran (auditory). Dampak nonauditory antara lain meliputi gangguan keseimbangan, sistem kardiovaskular, gangguan kualitas tidur dan gangguan kejiwaan (stres). Dampak auditory meliputi tinnitus atau telinga ber-

Alamat Korespondensi: Jumali, Departemen Kesehatan Lingkungan FKM Universitas Airlangga, Kampus C, Jl. Mulyorejo Surabaya 60115, Hp. 08165457755,e-mail:7um4li@gmail.com 
dengung, kesulitan membedakan kata berfrekuensi tinggi dan dampak auditory yang paling serius adalah ketulian jenis sensorineural (sensorineural hearing loss). ${ }^{3}$ Gangguan pendengaran akibat bising atau noise induced hearing loss (NIHL) adaalah gangguan pendengaran tipe sensorineural yang disebabkan oleh pajanan bising yang cukup keras dalam jangka waktu yang cukup lama, biasanya akibat bising lingkungan kerja. Pada mulanya, pengaruh kebisingan pada pendengaran bersifat sementara dan pemulihan terjadi secara cepat apabila kerja di tempat bising dihentikan, tetapi paparan kebisingan yang terjadi secara terus-menerus, menyebabkan kehilangan daya dengar yang menetap yang tidak pulih disebut kehilangan daya dengar permanen.1,4

Pelabuhan penyeberangan Ketapang-Gilimanuk termasuk yang sangat ramai setelah pelabuhan penyeberangan Merak-Bakauheni. Selat Bali yang memisahkan pelabuhan Ketapang dan Gilimanuk berjarak sekitar 6 $\mathrm{km}$ dapat ditempuh dalam waktu sekitar 45 menit. PT ASDP Indonesia Ferry selaku operator pelabuhan penyeberangan Ketapang-Gilimanuk, setiap hari, mengoperasikan 36 kapal feri, mempekerjakan sekitar 1.200 orang operator pelayaraan, dan 319 orang di antaranya adalah operator di ruang mesin yang setiap hari terpajan dengan kebisingan yang dihasilkan oleh mesin kapal.5,6

Kapal adalah kendaraaan air dalam bentuk dan jenis tertentu yang digerakkan tenaga angin, mekanik, dan energi lain yang ditarik atau ditunda. Kapal termasuk kendaraan berdaya dukung dinamis, kendaraan di bawah permukaan air serta alat dan bangunan terapung yang tidak berpindah-pindah. ${ }^{5}$ Perairan Indonesia yang luas memiliki banyak pulau yang besar dan kecil, memerlukan sarana transportasi laut. Salah satu jenis angkutan yang banyak terdapat di negara kepulauan adalah jenis kapal penyebrangan (kapal feri). ${ }^{5}$ Sumber utama kebisingan di kapal adalah kamar mesin yang di dalamnya terdapat mesin induk, mesin bantu, pompa, dan peralatan lain yang menyebabkan kebisingan dengan bentuk dan intensitas yang bervariasi, terutama ketika kapal berlayar. Kebisingan berlebihan yang dihasilkan mesin juga dapat membahayakan kesehatan operator dan mengganggu kelancaran berkomunikasi di atas kapal. ${ }^{7}$

Masih banyak kapal feri dengan intensitas kebisingan di ruang mesin melebihi nilai ambang batas (> $85 \mathrm{dBA}$ ). Hal tersebut dibuktikan dari hasil pengukuran kebisingan acak yang dilakukan di ruang mesin kapal feri oleh petugas Kantor Kesehatan Pelabuhan Probolinggo wilayah Kerja Pelabuhan Banyuwangi. Pengukuran yang dilakukan terhadap 20 kapal feri yang beroperasi menemukan 12 kapal (60\%) dengan intesitas kebisingan > $85 \mathrm{dBA}$. Hasil pengamatan dan wawancara yang dilakukan selama ini terhadap operator mesin di kapal feri menunjukkan gangguan pendengaran akibat bising, antara lain intensitas pembicaraan yang cenderung keras dan sering melakukan pengulangan kata-kata dalam berkomunikasi sehari-hari. Penelitian ini bertujuan menganalisis prevalensi NIHL dan faktor risiko yang berpengaruh pada operator mesin kapal feri penyeberangan Ketapang-Gilimanuk.

\section{Metode}

Penelitian observasional dengan desain penelitian cross-sectional ini dilaksanakan pada periode Januari Agustus 2013, pengumpulan data dilakukan pada periode Maret - Juni 2013 di pelabuhan penyeberangan Ketapang-Gilimanuk. Populasi adalah petugas operator mesin yang bekerja di 36 kapal feri yang beroperasi di pelabuhan penyeberangan Ketapang-Gilimanuk yang berjumlah 319 orang dan sampel minimal dihitung dengan rumus sampel minimal estimasi proporsi. Penarikan sampel dilakukan dengan metode simple random sampling pada seluruh petugas operator mesin kapal (36 kapal) yang beroperasi di pelabuhan penyeberangan Ketapang-Gilimanuk. Pengundian secara acak dilakukan pada sejumlah operator yang ada di setiap kapal untuk memilih satu hingga dua operator sebagai sampel dan sebanyak 66 operator mesin kapal feri terpilih sebagai sampel penelitian. Variabel bebas meliputi intensitas kebisingan ruang mesin dan karakterisitik operator meliputi umur, lama paparan, massa kerja, hobi atau pekerjaan lain yang berhubungan dengan bising, penggunaan APT, penggunaan obat ototoksik, dan terpajan bising di tempat tinggal. Variabel terikat adalah tuli akibat bising atau NIHL.

Data karakteristik responden dikumpulkan dengan wawancara menggunakan kuesioner. Intensitas kebisingan ruang mesin kapal feri diukur menggunakan sound level meter yang telah dikalibrasi dan data tuli akibat bising (NIHL) yang diperoleh dengan pemeriksaan audiometri nada murni pada frekuensi 500, 1.000, 2.000, dan $4.000 \mathrm{~Hz}$ pada hantaran udara dan hantaran tulang dengan pembacaan dengan audigram. Variabel dependen adalah kejadian NIHL dan variabel independen intensitas kebisingan ruang mesin kapal dan karakteristik subjek yang meliputi usia, lama paparan, masa kerja, pekerjaan lain terkait bising, penggunaan APT, obat ototoksik, bising di tempat tinggal dan kebiasaan merokok. Analisis bivariat untuk variabel dependen kandidat model multivariat. Analisis multivariat metoda regresi logistik digunakan untuk menganalisis berbagai faktor yang memengaruhi kejadian NIHL.

\section{Hasil}

Intensitas kebisingan di ruang mesin kapal feri diukur menggunakan sound level meter type Soundpro SE/DL/BIF090006. Kapal feri yang intensitas kebisingan di ruang mesinnya $\leq 85 \mathrm{dBA}$ adalah $13(36 \%)$ kapal dan yang melebihi nilai ambang batas yaitu $>85 \mathrm{dBA}$ terda- 
Tabel 1. Hasil Analisis Bivariat Faktor Risiko Noise Induced Hearing Loss (NIHL) pada Operator Mesin Kapal Feri

\begin{tabular}{|c|c|c|c|c|c|c|c|}
\hline \multirow{3}{*}{ Variabel } & \multirow{3}{*}{ Kategori } & \multicolumn{4}{|c|}{ NIHL } & \multirow{3}{*}{ Nilai p } & \multirow{3}{*}{ PR } \\
\hline & & \multicolumn{2}{|c|}{ Ya } & \multicolumn{2}{|c|}{ Tidak } & & \\
\hline & & $\mathbf{n}$ & $\%$ & $\mathbf{n}$ & $\%$ & & \\
\hline \multirow[t]{2}{*}{ Intensitas kebisingan (dBA) } & $>85$ & 20 & 48,8 & 21 & 51.2 & $0,006^{*}$ & 4.065 \\
\hline & $\leq 85$ & 3 & 12,0 & 22 & 88.0 & & \\
\hline \multirow[t]{2}{*}{ Usia (tahun) } & $\geq 40$ & 17 & 60,7 & 11 & 39.3 & $0,000 *$ & \\
\hline & $<40$ & 6 & 15,8 & 32 & 84.2 & & \\
\hline \multirow[t]{2}{*}{ Masa kerja (tahun) } & $\geq 10$ & 17 & 50,0 & 17 & 50.0 & $0,016^{*}$ & 2.66 \\
\hline & $<10$ & 6 & 18,8 & 26 & 81.2 & & \\
\hline \multirow[t]{2}{*}{ Lama paparan (jam/minggu) } & $>40$ & 21 & 41,2 & 30 & 58.8 & 0,093 & \\
\hline & $\leq 40$ & 2 & 13,3 & 13 & 86.7 & & \\
\hline \multirow[t]{2}{*}{ Hobi terkait bising } & Ya & 8 & 53,3 & 7 & 46.7 & 0,087 & \\
\hline & Tidak & 15 & 29,4 & 36 & 70.6 & & \\
\hline \multirow[t]{2}{*}{ Konsumsi obat ototoksik } & $\mathrm{Ya}$ & 5 & 71,4 & 2 & 28.6 & $0,045^{*}$ & 2.34 \\
\hline & Tidak & 18 & 30,5 & 41 & 69.5 & & \\
\hline \multirow[t]{2}{*}{ Penggunaan alat pelindung telinga } & $\mathrm{Ya}$ & 5 & 71,4 & 2 & 28.6 & & \\
\hline & Tidak & 18 & 30,5 & 41 & 69.5 & & \\
\hline \multirow[t]{2}{*}{ Bising lingkungan tinggal } & Ya & 4 & 66,7 & 2 & 33.3 & 0,172 & \\
\hline & Tidak & 19 & 31,7 & 41 & 68.3 & & \\
\hline \multirow[t]{2}{*}{ Kebiasaan merokok } & Ya & 18 & 37,5 & 30 & 62.5 & 0,654 & \\
\hline & Tidak & 5 & 27,8 & 13 & 72.2 & & \\
\hline
\end{tabular}

Keterangan : *) signifikan pada $\alpha=0,05 ; \mathrm{PR}=$ prevalence ratio ; NIHL = Noise Induced Hearing Loss

Tabel 2. Analisis Stratifikasi Intensitas Kebisingan Ruang Mesin dan Karakteristik Operator Mesin Kapal terhadap NIHL

\begin{tabular}{llll}
\hline Intensitas bising & Variabel & Nilai p & PR \\
\hline & Usia & & \\
$>85 \mathrm{dBA}$ & $>40$ tahun & $0.003^{*}$ & 2.98 \\
& $<40$ tahun & & \\
$\leq 85 \mathrm{dBA}$ & $>40$ tahun & 1.000 & \\
& $<40$ tahun & & \\
$>85 \mathrm{dBA}$ & Lama paparan & & \\
& $>40$ jam/minggu & $0.020^{*}$ & \\
$\leq 85 \mathrm{dBA}$ & $<40$ jam/minggu & & \\
& $>40$ jam/minggu & 1.000 & \\
& $<40$ jam/minggu & & \\
\hline
\end{tabular}

Keterangan : *) signifikan pada $\alpha=0,05$

pat 23 (64\%) kapal. Intensitas kebisingan ruang mesin terendah adalah 80,5 dBA dan tertinggi adalah 89,4 dBA. Rerata nilai ambang dengar telinga responden pada frekuensi 500,1.000, 2.000 dan $4.000 \mathrm{~Hz}$, responden yang telinga kanan dan kirinya normal adalah 27 $(40,90 \%)$ responden. Responden yang mengalami jenis gangguan tuli konduktif sebesar $16(24,24 \%)$ dan responden yang mengalami gangguan pendengaran jenis tuli sensorineural sebesar $23(34,85 \%)$. Analisis bivariat menunjukkan semua variabel yang diamati memenuhi kriteria kandidal model multivariat kejadian NIHL ( $\mathrm{p}<$ $0,25)$ kecuali status merokok (Tabel 1).

Analisis multivariat menggunakan metode analisis regresi logistik. Pada variabel yang diduga mempengaruhi kejadian NIHL dilakukan uji secara serentak untuk mengetahui berbagai variabel yang memengaruhi kejadi-
Tabel 3. Variabel Determinan Tuli Sensorineural pada Operator Mesin Kapal

\begin{tabular}{llll}
\hline Variabel & B & Wald & Nilai p \\
\hline Intensitas bising & -0.284 & 3.234 & 0.072 \\
Usia & -0.108 & 10.412 & $0.001^{*}$ \\
Masa kerja & 0.076 & 1.157 & 0.282 \\
Lama paparan & -1.034 & 4.908 & $0.027^{*}$ \\
Hobi terkait bising & -0.385 & 0.200 & 0.654 \\
Obat ototoksik & -0.67 & 0.002 & 0.963 \\
Penggunaan alat pelindung telinga & 1.282 & 1.489 & 0.222 \\
Bising tempat tinggal & 0.723 & 0.406 & 0.524 \\
Merokok & -0.667 & 0.590 & 0.443 \\
\hline
\end{tabular}

Keterangan : *) signifikan pada $\alpha=0.05$

an NIHL secara bersamaan pada operator mesin kapal feri dengan kriteria nilai $\mathrm{p}<$ nilai $\alpha=0,05$. Hasil analisis regresi logistik menemukan variabel tersebut adalah umur dan lama paparan (Tabel 3).

\section{Pembahasan}

Pengukuran intensitas kebisingan di ruang mesin kapal feri di pelabuhan penyeberangan Ketapang menemukan 63,89\% kapal dengan kebisingan > 85A dBA. International Maritim Organisation (IMO) dalam annex Code on Noise Levels on Board Ship - Chapter 4 Maximum Acceptable Sound Pressure Levels, ${ }^{6}$ menyebutkan standar kebisingan ruang mesin tempat awak kapal berada terus menerus di ruang mesin (continuously manned) adalah $90 \mathrm{dBA}$, di ruang kontrol (machinery control rooms) $75 \mathrm{dBA}$ dan kewajiban menggunakan alat 
pelindung telinga apabila memasuki ruangan yang intensitas kebisingannya $>85 \mathrm{dBA}$.

Proses pembuatan kontruksi kapal dan persyaratan teknis yang lain mengacu pada peraturan IMO. Fakta di lapangan menemukan beberapa kapal dengan tahun pembuatan yang baru tapi dengan intensitas kebisingan $>85 \mathrm{dBA}$. Hal tersebut dapat menjadi salah satu penyebab kapal dengan intesitas kebisingan $>85 \mathrm{dBA}$. IMO juga mengatur kewajiban menggunakan alat pelindung telinga apabila memasuki ruangan dengan intensitas kebisingan $>85 \mathrm{dBA}$.

Kementerian Tenaga Kerja dan Transportasi Republik Indonesia menetapkan $85 \mathrm{dBA}$ sebagai nilai ambang batas kebisingan. Lebih lanjut ditetapkan, untuk $85 \mathrm{dBA}$ waktu yang diperkenankan untuk bekerja adalah 8 jam sehari atau 40 jam seminggu, untuk $95 \mathrm{dBA}$ hanya 47 menit, $100 \mathrm{dBA}$ hanya 15 menit, 105 hanya 4 menit, 110 dBA hanya 1 menit. ${ }^{8,9}$ Bising di lingkungan kerja dengan intensitas bising $>85 \mathrm{dBA}$ dapat menyebabkan NIHL. ${ }^{10}$ Menurut Alberti, 11 bising yang bersifat menetap lebih merusak dibandingkan dengan bising yang lain. Sifat kebisingan ruang mesin kapal digolongkan bising yang menetap sehingga intensitas kebisingan $>85 \mathrm{dBA}$ yang bersifat menetap ditambah lama paparan yang melebihi 40 jam/minggu tanpa penggunaan alat pelindung telinga yang memadai. Kebisingan di ruang mesin kapal feri di pelabuhan penyeberangan dapat menimbulkan gangguan pendengaran pada operator yang setiap hari bekerja di ruangan mesin.

Prevalensi NIHL pada operator mesin kapal feri di penyeberangan Ketapang-Gilimanuk adalah 34,85\%. Angka Prevalensi yang didapat lebih rendah daripada angka prevalensi NIHL pada beberapa penelitian lain. Chang dan Chang, ${ }^{12}$ menemukan 56,8\% dari pekerja lapangan di perusahaan LPG di Taiwan mengalami NIHL. Shrestha, ${ }^{13}$ meneliti 110 polisi lalu lintas yang bertugas di Kathmandu India menemukan $(66,4 \%)$ mengalami NIHL, 40,9\% jenis bilateral dan 25,4\% unilateral. Penelitian sebelumnya meneliti pekerja di perusahaan baja di Pulau Jawa menemukan prevalensi NIHL sebesar 43,6\%. ${ }^{14}$ Angka prevalensi tuli sensorineural 35\% lebih tinggi apabila dibandingkan dengan pekerja logam di Brazil, Guerra et al, ${ }^{15}$ menemukan prevalensi kasus NIHL adalah 15,9\% pada pekerja logam di Brazil yang terpapar kebisingan 83 - 102 dBA yang mana mereka menjalani program konservasi pendengaran. Prevalensi gangguan pendengaran akibat bising dari tahun ke tahun cenderung meningkat, di Thailand meningkat dari tahun $1988(28,1 \%)$ ke tahun $2001(35,2 \%) .16$

Kejadian NIHL pada operator mesin kapal feri disebabkan oleh paparan intensitas bising $80,5-89,4 \mathrm{dBA}$ yang diterima operator pada usia $>40$ tahun dengan lama paparan $\geq 40 \mathrm{jam} / \mathrm{minggu}$. Ciri khas gangguan pendengaran akibat bising adalah bersifat sensorineural dan hampir selalu terjadi secara bilateral pada kedua telinga. ${ }^{17}$ Hasil uji beda pada rerata nilai ambang dengar telinga kanan dan kiri operator yang mengalami NIHL menunjukkan tidak ada perbedaan yang signifikan antara rerata nilai ambang dengar telinga kanan dan kiri pada operator mesin kapal yang mengalami NIHL yaitu $\mathrm{p}=$ 0,326 (>0,05), temuan ini menunjukkan bahwa efek kebisingan yang merugikan umumnya bersifat bilateral dan simetris pada kedua telinga. ${ }^{17-19}$

Melihat dari struktur dalam ruangan mesin kapal yang tertutup, sumber suara dari mesin induk dan mesin bantu dipantulkan ke dinding plat baja kembali ke ruangan. Hasil pengukuran di beberapa lokasi di kamar mesin menunjukkan tidak ada perbedaan intensitas kebisingan yang berarti antarlokasi di dalam kamar mesin, hal ini dapat dijadikan alasan bahwa operator mesin mendapatkan paparan kebisingan secara bilateral, antara telinga kanan dan kiri sehingga menghasilkan efek yang simetris dan bilateral. ${ }^{10,17,18}$

Pengaruh umur terhadap NIHL disebabkan pajanan kebisingan $>85 \mathrm{dBA}$ dengan masa kerja $>10$ tahun. Umur responden bersinergi dengan intensitas kebisingan dan masa kerja berisiko memengaruhi kejadian NIHL pada operator mesin kapal feri. NIHL yang terjadi pada umur $\geq 40$ tahun selain berhubungan dengan faktor bising, kemungkinan berhubungan dengan penurunan ambang pendengaran karena faktor usia atau presbiakusis. Faktor usia dan kebisingan umumnya dianggap penyebab paling umum kehilangan pendengaran dewasa di negara maju. Paparan kebisingan kerja menyumbang kurang dari $10 \%$ dari beban gangguan pendengaran dewasa di Amerika Serikat, sebagian besar sisanya adalah berkaitan dengan umur dan paparan kebisingan diatas 95 dBA tanpa perlindungan telinga. 4,11,20

Hasil studi ini tidak berbeda jauh dengan hasil studi lai, Guerra, ${ }^{15}$ dalam studi cross-sectional pada perusahaan logam di Rio de Janeiro, Brasil, menemukan peningkatan prevalensi NIHL secara signifikan berbanding lurus dengan peningkatan umur, masa kerja dan lama paparan kebisingan kerja. Penelitian yang meneliti pekerja di perusahaan baja di Pulau Jawa didapatkan hubungan bermakna antara peningkatan umur dengan peningkatan kejadian gangguan pendengaran akibat bising. ${ }^{14}$

Lama jam kerja sehari berdasarkan Undang-Undang Republik Indonesia Nomor 13 tahun 2003 pasal 77 (1) adalah 8 jam sehari dan 40 jam seminggu dengan waktu istirahat minimal setengah jam sehari. Sebesar 51 $(77,3 \%)$ responden terpapar kebisingan $>40$ jam/minggu, $32(48,5 \%)$ di antaranya terpapar kebisingan $>85$ dBA. Kejadian NIHL pada operator mesin kapal di penyeberangan Ketapang-Gilimanuk disebabkan karena terpajan kebisingan yang melebihi NAB yaitu $85 \mathrm{dBA}$ selama $40 \mathrm{jam} / \mathrm{minggu}$. Bising di lingkungan kerja dengan intensitas bising $>85 \mathrm{dBA}$ dapat menyebabkan noise in- 
duced hearing loss. ${ }^{11}$ Selain disebabkan oleh paparan melebihi NAB, kejadian NIHL juga disebabkan oleh pola sif kerja dan pola istirahat operator yang tidak teratur. Pola sif kerja yang ada di kapal feri termasuk operator ruang mesin adalah 2 sif kerja selama 24 jam yang berarti operator bekerja di kapal selama 24 jam dan istirahat pulang ke rumah selama 24 jam, ada juga yang menerapkan sistem shift kerja 2 x 24 jam kerja dengan waktu istirahat di rumah juga 2 × 24 jam dan bahkan ada yang yang sampai 5 hari bekerja terus menerus dengan harapan dapat libur dirumah selama 5 hari juga. Sistem jaga mesin bagi operator adalah 6 jam/12 jam, operator melakukan jaga di ruang mesin selama 6 jam, istirahat 6 jam dan akan jaga lagi setiap 6 jam dalam sif kerjanya. Pola sif yang diterapkan di kapal feri jelas berdampak pada sistem pendengaran operator, ketika recovery pendengaran belum sepenuhnya kembali petugas sudah harus terpapar lagi dengan kebisingan.

Kebisingan dengan intensitas yang lebih besar dari 85 dBA selama 8 jam/hari akan dibutuhkan waktu istirahat antara $3-7$ hari. Pola sif yang berlaku di kapal jelas akan menambah parah kerusakan ujung saraf pada sistem pendengaran operator kapal, dan mempercepat terjadinya ketulian menetap karena waktu yang dibutuhkan untuk recovery sistem pendengaran tidak mencukupi. ${ }^{11,20}$ Akibat pajanan bising dengan intensitas tinggi, tenaga kerja akan mengalami penurunan daya dengar yang bersifat sementara. Apabila tenaga kerja diberikan waktu istirahat yang cukup, daya dengar akan pulih pada ambang pendengaran semula (recovery dapat sempurna). Namun, apabila waktu istirahat tidak cukup dan tenaga kerja terpajan kembali dengan bising dan keadaan ini berlangsung dalam jangka waktu yang lama, ketulian sementara bertambah dan akhirnya merusak ujung syaraf dan mengakibatkan ketulian menetap atau permanent threshold shift (PTS). 11,20

Hasil penelitian ini sesuai dengan penelitian sebelumnya, lama jam kerja berhubungan secara signifikan dengan kejadian gangguan pendengaran tipe sensorineural (nilai $\mathrm{p}=0,009$ ). Hasil penelitian juga menyebutkan bahwa tenaga kerja yang melakukan pekerjaan lebih dari $40 \mathrm{jam} / \mathrm{minggu}$ mengalami risiko gangguan pendengaran tipe sensorineural sebesar 7,33 kali lebih besar daripada tenaga kerja yang melakukan pekerjaan $\leq 8$ jam sehari atau $40 \mathrm{jam} / \mathrm{minggu} .21,22$

\section{Kesimpulan}

Intensitas kebisingan di ruang mesin kapal feri yang $>$ 85 dBA ditemukan pada 23 (64\%) kapal. Intensitas kebisingan ruang mesin terendah adalah $80,5 \mathrm{dBA}$ dan tertinggi adalah 89,4 dBA. Prevalensi NIHL pada operator mesin kapal feri penyeberangan Ketapang - Gilimanuk adalah $34,8 \%$. Intensitas kebisingan ruang mesin, umur responden, masa kerja responden dan lama paparan dan penggunaan obat ototoksik merupakan faktor risiko yang memengaruhi kejadian NIHL pada operator mesin kapal feri. Faktor risiko yang secara dominan memengaruhi kejadian NIHL pada operator mesin kapal feri adalah usia operator dan lama paparan operator dengan kebisingan.

\section{Saran}

Penurunan intensitas kebisingan ruang mesin dapat dilakukan dengan memasang peredam suara pada dinding, atap dan lantai ruang mesin dengan bahan yang menyerap energi bising. Perlu penyediaan ruang kontrol (control room) di ruang mesin agar operator tidak terpapar langsung dengan kebisingan ruang mesin. Penambahan jumlah operator dapat dipertimbangkan untuk menambah waktu istirahat atau libur bagi operator sehingga proses recovery pendengaran dapat maksimal. Mengubah tata cara kerja seperti merubah daftar kerja dan pola sif operator yang pada hasil akhirnya dapat mengurangi waktu paparan operator terhadap kebisingan. Edukasi tentang bahaya bising pada operator kapal agar mengerti serta rela mengusahakan perlindungan diri sendiri terhadap bising. Pemasangan poster dan tanda pada daerah dengan kebisingan tinggi sehingga operator tahu dan berusaha melindungi dirinya dengan alat pelindung telinga atau tidak berada dalam tempat bising dalam waktu yang lama. Setiap perusahaan pelayaran perlu penerapan program konservasi pendengaran yang mencakup kegiatan pengawasan kebisingan, perlindungan pendengaran, tes pendengaran, dan pelatihan.

\section{Daftar Pustaka}

1. Gubata ME, Packnett ER, Feng X, Suma'mur. Higiene perusahaan dan kesehatan kerja (Hiperkes). Jakarta: CV Sagung Seto; 2009.

2. Kementerian Kesehatan Republik Indonesia. Nomor 879/Menkes/SK/$\mathrm{XI} / 2006$ tentang Rencana Strategi Nasional Penanggulangan Gangguan Pendengaran dan Ketulian Untuk Mencapai Sound Hearing 2030. Jakarta: Kementerian Kesehatan Republik Indonesia; 2006.

3. Gubata ME, Packnett ER, Feng X, Cowan DN, Niebuhr DW. Preenlistment hearing loss and hearing loss disability among US soldiers and marines, noise and health. A Bimonthly Interdicyplinary International Journal. 2013; 15(66): 289-95.

4. Lintong F. Gangguan pendengaran akibat bising. Jurnal Biomedik. 2009; 1(2).

5. Kementerian Sekretariat Negara. Undang-Undang Republik Indonesia Nomor 17 tahun 2008 tentang Pelayaran. Jakarta: Kementerian Sekretariat Negara; 2008.

6. International Maritime Organization (IMO). Code on noise levels on board ship chapter 4 - Maximum acceptable sound pressure levels. Resolution A.468 (XII) 198.1981. Available from: www.imo.org/blast/blastData.asp?doc_id=9595\&filename.pdf.

7. Yudo H, Jokosisworo S. Standar kebisingan suara di kapal. Jurnal Kapal. 2006; 3 (3).

8. Kementerian Tenaga Kerja dan Transmigrasi Republik Indonesia. NOMOR 25/MEN/XII/2008 tentang Pedoman Diagnosis dan Penilaian 
Cacat Karena Kecelakaan dan Penyakit Akibat Kerja. Jakarta: Kementerian Tenaga Kerja dan Transmigrasi Republik Indonesia; 2008.

9. Kementerian Tenaga Kerja dan Transmigrasi Republik Indonesia. Nomor 13/MEN/X/2011 tentang nilai ambang batas fisika dan faktor kimia di tempat Kerja. Jakarta: Kementerian Tenaga Kerja dan Transmigrasi Republik Indonesia; 2011.

10. Rusiyanti, Nurjazuli, Suhartono. Hubungan paparan kebisingan dengan gangguan pendengaran pada pekerja industri kerajinan pandai besi di Desa Hadipolo Kecamatan Kabupaten Kudus. Jurnal Kesehatan Lingkungan Indonesia. 2012; 11

11. Alberti PW, Occupational hearing loss, disease of the ear nose and throat. In : Ballenger JJ, editor. 14th ed. London: Lea and Febiger, 1991.

12. Chang SJ, Chang CK. Prevalence and risk factors of noise-induced hearing loss among Liquefied Petroleum Gas (LPG) cylinder infusion workers in Taiwan. Industrial Health. 2009; 47: 603-610.

13. Shrestha I, Shrestha BL, Pokharel M, Amatya RCM, Karki DR. Prevalence of noise induced hearing loss among traffic police personnel of Kathmandu Metropolitan City. Kathmandu Univesity Medical Journal. 2011; 36 (4): 274-8.

14. Warwick W. The epidemiology of noise expousure in Australia workforce. Noise and Health. A bimonthly Interdicyplinary International Journal 2013; 15(66): 326-31.
15. Guerra MR, Laurenco PMC, Eresa M. Prevalence of noise induced hearing loss in Metallurgical Company. Review Saude Publica Brazil. 2005; 39 (2): 1-7.

16. Viraporn A. Evaluation of noise induced hearing loss with audiometer and distortion product otoacoustic emissions. Journal of Medical Association of Thailand, 2008; 91 (7): 1066-71.

17. Kirchner D, Eric BE, Dobie RA, Rabinowitz P, Crawford J, Kopke R, et al. Occupational noise-induced hearing loss. Journal of Occupational \& Environmental Medicine. 2012; 54(1): 106-8.

18. Rambe AYM. Gangguan pendengaran akibat bising. Medan: Universitas Sumatera Utara; 2003.

19. Soeripto M. Hygene industri. Jakarta: Balai Penerbit Fakultas Kedokteran Universitas Indonesia; 2008.

20. Purdy S, Williams W. Guidelines for audiometry for diagnosis of NIHL. Sydney Australia: National Acoustic Laboratories; 2012.

21. Dobie RA. The burdens of age-related and occupational noise-induced hearing loss in the United States. Journal Ear and Hearing. 2008; 29 (4): 565-77.

22. Arini EY. Faktor-faktor yang berhubungan dengan gangguan pendengaran tipe sensorineural tenaga kerja unit produksi di PT. Kurnia Jati Utama Semarang [tesis]. Semarang: Program Pasca Sarjana Magister Kesehatan Lingkungan Universitas Diponegoro; 2005. 